\title{
Towards Analysis and Optimization of Electrospun PVP (Polyvinylpyrrolidone) Nanofibers
}

\author{
Utkarsh (D), ${ }^{1}$ Hussien Hegab, ${ }^{2}$ Muhammad Tariq, ${ }^{1}$ Nabeel Ahmed Syed, ${ }^{1}$ Ghaus Rizvi, ${ }^{1}$ \\ and Remon Pop-Iliev ${ }^{1}$ \\ ${ }^{1}$ Ontario Tech University, 2000 Simcoe Street North, Oshawa, Ontario, Canada L1G0C5 \\ ${ }^{2}$ Mechanical Design and Production Engineering Department, Cairo University, Giza 12613, Egypt \\ Correspondence should be addressed to Utkarsh; fnu.utkarsh@ontariotechu.net
}

Received 10 December 2019; Revised 26 March 2020; Accepted 3 April 2020; Published 4 May 2020

Academic Editor: Alexandra Muñoz-Bonilla

Copyright ( 2020 Utkarsh et al. This is an open access article distributed under the Creative Commons Attribution License, which permits unrestricted use, distribution, and reproduction in any medium, provided the original work is properly cited.

\begin{abstract}
In this study, the polymeric nanofibers of polyvinylpyrrolidone (PVP) were manufactured using the electrospinning technique. The electrospinning process parameters such as voltage, polymer concentration, rotational speed of the collecting drum, collecting distance, and flow rate were optimized to obtain the minimum fiber diameter for sound absorption applications. The effects of these parameters on the fiber diameter as output responses were investigated by analysis of variance (ANOVA) and Taguchi's array design. Furthermore, a mathematical model was generated using response surface methodology (RSM) to model the electrospinning process. The high voltage and polymer concentration were observed to be the most significant parameters at 95\% and 99\% confidence level. The average model accuracy of $83.4 \%$ was observed for the predictive model of electrospinning which is considered acceptable as it is composed of complete experimental trials of 27 out of 243 runs. The experimental study offers a promising attempt in the open literature to carefully understand the effect of various electrospinning parameters when producing PVP nanofibers.
\end{abstract}

\section{Introduction}

Electrospinning is a well-established and straightforward method of manufacturing nanofibers from different materials like polymers, ceramics, and metals. The process is carried out in the presence of high electric field which results in stretching of polymer solution that produces fibers which are in micro-/nanoscale $[1,2]$. The electrospun nanofiber produced from this technique offers exceptional properties like high surface area to volume ratio, flexibility, high porosity, and better aspect ratio which makes it suitable for various industrial applications. These applications include tissue engineering, filtration, medical and personal care, sensors, sound absorption, energy harvesting, and storage $[3,4]$.

The working principle of the electrospinning process involves the application of an electric charge to the polymer solution, and the solution jet stretches in a high electric field to produce nanofibers. So, when the polymer solution flows out from the needle connected to a high-voltage DC power supply, it stretches out and elongates itself to a conical shape which is known as the Taylor cone. The conical droplet at this point crosses the surface tension with increasing electric field, and the charged polymer jet extrudes out in the form of fibers due to the generated electrostatic force. The thin stretched fibers travel faster towards the collector end due to the opposite charge and are accumulated on it in the form of fiber webs [5-7].

The nanofiber morphology is dependent on several parameters involved in the electrospinning process. The parameters are grouped into three different categories as follows: (a) solution parameters (concentration, viscosity, surface tension, molecular weight, and solvent type), (b) processing parameters (voltage, solution flow rate, needle-collector distance, needle tip design, collector geometry, and velocity), and (c) ambient parameters (temperature and humidity). Therefore, the desired morphology of the fibers can be 
achieved by optimizing and modeling the electrospinning parameters $[8,9]$. The effect of these parameters on fiber geometry has been investigated in different studies by numerous scholars.

The viscosity of the polymer solution can be regulated by varying the concentration, and it is the most important factor that affects the fiber morphology and diameter values. Tao and Shivkumar [10] used Polyvinyl Alcohol (PVA) and studied the effect of concentration (7-33 wt\%) on fiber morphology. They observed that for the lower concentration of $7-16 \mathrm{wt} \%$, spray patterns and beads were obtained. The uniform and smooth nanofibers were obtained at a concentration of $22 \mathrm{wt} \%$, and a ribbon like structure was obtained with concentrations higher than $24 \mathrm{wt} \%$. Deitzel et al. [11] investigated the effect of Polyethylene Oxide (PEO) concentration (range: $4 \mathrm{wt} \%$ to $10 \mathrm{wt} \%$ ) on the fiber diameter and observed that the fiber diameter increased with the increase in concentration. Koski et al. [12] and Boland et al. [13] observed the same phenomena using PVA and polyglycolic acid. Thus, the concentration of polymer plays an important role in manufacturing fibers with control on fiber diameters and bead formation [14]. Reneker and Chun [15] concluded the dependence of concentration on the fiber diameter of PEO electrospun nanofibers and also investigated the insignificant change in the diameter with the change in voltage. Zhang et al. [16] observed that the fiber diameter of PVA nanofibers increased with the increase in high voltage. Several researchers like Yuan et al. [17] and Katti et al. [18] claim that the higher voltages facilitate the formation of smaller fibers because of the increase in electrostatic repulsive forces. Hence, it was observed that the fiber diameter depends on voltage but the effect is not significant when compared to the concentration of polymers. The flow rate is also an important factor which affects the velocity of the jet and fiber diameter. Dersch et al. [19] observed that the fiber diameter of PSF (polysulfone) increases with the increase in flow rate. In general, a lower flow rate is preferred to avoid beaded fibers as the solution gets enough time to dry with higher stretching forces on jet. Yuan et al. [17] investigated the morphological change on PSF fibers with the change in flow rate and observed lower diameters at a lower flow rate. The distance between the collector screen and the needle regulates the electric field intensity which in turn controls the fiber morphology. Lower distance escapes solvent drying, and fibers stick to each other forming larger diameter fibers whereas higher distance requires high voltage for fiber formation [20]. The solvent drying phenomenon is an important aspect as it morphs the fiber geometry, so distance needs to be optimized. Yuan et al. [17] observed lower diameter values at larger distances. The process parameter affects the fiber diameter, but the level of significance differs from that of solution concentration [21]. The effects of various parameters on the fiber properties are summarized in Table 1.

The electrospinning process of manufacturing fibers is a complex process wherein different parameters affect the fiber morphology and diameter. The correlation between these parameters and respective fiber geometries is yet to be studied to obtain desired small smooth/fine nanofibers without
TABLE 1: Effect of electrospinning factors on fiber morphology.

\begin{tabular}{ll}
\hline $\begin{array}{l}\text { Control } \\
\text { parameters }\end{array}$ & Effects on fiber morphology \\
\hline & $\begin{array}{l}\text { (i) The fiber diameter value reduces with the } \\
\text { increase in voltage supplied due to the higher } \\
\text { stretching of polymer solution [17]. }\end{array}$ \\
High voltage & $\begin{array}{l}\text { (ii) Higher voltage will increase the evaporation } \\
\text { rate that dries the solvent faster [28, 29]. } \\
\text { (iii) Lower voltage values result in reduced flight } \\
\text { time of the polymer jet, which increases the } \\
\text { possibility of obtaining smoother fibers [30]. }\end{array}$
\end{tabular}

(i) The fiber diameter value increases with a higher concentration of polymer solution.

(ii) With lower concentrations, defects in the

Concentration form of beads start to appear on the nanofiber mat.

(iii) Possibility of electrospraying also increases on lower concentrations $[8,12]$.

(i) The average fiber diameter value is higher with a stationary rotor than a rotating collector.

Rotational (ii) The diameter of fibers decreases with an speed increase in rotating collector RPM, but the decrease in value is not significant compared to other parameters [31].

(i) Increasing the distance will increase the time of flight, resulting in stretched and further elongated fibers [30].

(ii) Beads start to appear with a higher distance

$\begin{array}{ll}\text { Collecting } & \text { between the needle } \& \text { the collector. } \\ \text { distance } & \text { (iii) Formation of beads also takes place with lower }\end{array}$ distances as the polymer jet does not experience a sufficient time to solidify $[32,33]$.

(iv) The optimum distance is required to obtain smooth fibers [17].

(i) The fiber diameter decreases with the lower flow rate of polymer solution because it provides more time for stretching [17].

Flow rate

(ii) Higher flow rate values yielded thicker fibers with beads as the drying time for the fibers reduces [33].

beads. Several efforts have been made by researchers to model the process, but these studies include only a limited number of variables. Reneker et al. [22] investigated the factors that are responsible for polymer jet instability and developed a model to analyze the phenomenon. Karatay and Dogan [23] investigated the whipping instability of the polymer jet by developing a mathematical model wherein they used a secondary electric field to deposit electrospun fibers in a small spot of specific size. The effect of conductivity on morphology of fibers has been studied in few models where several types of salts are added in the polymer solution and the as-spun fibers were analyzed to model the characteristics [24]. There are models that explain the effect of the electric field on jet thinning and different polymer solutions [25].

Polyvinylpyrrolidone (PVP) is a synthetic, water-soluble, and biocompatible polymer with low toxicity and better adhesiveness and solubility with various organic solvents. It 
has been widely used in electronics, cosmetics, paints, biological-based materials, and pharmaceutical industries. Pure PVP and its polylactide blends were first used for electrospinning to fabricate fibers in 2001. It has been widely used to manufacture fibers from different materials using the electrospinning process because of its spinability and fiber extraction. Several metal oxide filler materials like Titanium Oxide $\left(\mathrm{TiO}_{2}\right)$, Zinc Oxide ( $\left.\mathrm{ZnO}\right)$, and Tin(IV) Oxide $\left(\mathrm{SnO}_{2}\right)$ were mixed with PVP to manufacture nanofibers using the electrospinning method. Furthermore, conductive polymers, biopolymers, and other organic/inorganic compounds were used as a filler in the PVP polymer matrix and directly blended with the PVP solution to obtain PVP-based electrospun fibers. Studies on various solvents such as ethanol, water, N,N-dimethylformamide (DMF), dichloromethane (DCM), and methanol have been reported to investigate the potential of PVP nanofiber fabrication via the electrospinning process and its morphological variation $[26,27]$.

According to the literature, there exist very few published studies that investigated the effect of electrospinning process parameters (more than three) on the fiber morphology. Moreover, the complex electrospinning process can be optimized and modeled using the statistical tools to achieve the desired application-based fibers. The statistical models have been used in few research investigations to optimize the process where Albetran et al. [34] found the optimum values for tip concentration, flow rate, needle to collector distance, and applied voltage to minimize the diameter of $\mathrm{TiO}_{2} / \mathrm{PVP}$ nanofibers. Optimization of the collector distance, applied voltage, and concentration for polyacrylonitrile (PAN) nanofibers was conducted by Yördem et al. [21] using RSM. Research work has also been done on Bombyx mori silk, and an optimum combination for concentration and voltage was obtained [35]. The abovementioned exploratory literature has shown that the diameters and morphology of the fibers depend on a number of electrospinning parameters. However, the relationship between these parameters and fiber structure is still needed to be studied in detail. No extensive study has been reported which has examined the effect of multiple parameters in depth.

This current study involves the parametric evaluation of the electrospinning process to minimize the diameter of PVP nano-/microfibers for sound absorption applications. Previous studies on sound absorption professed that the sound absorption coefficient value increases with lower fiber diameters for a fiber-based membrane $[36,37]$. The concept of design of experiments (DOE) was implemented using Taguchi's orthogonal array (OA) design, analysis of variance (ANOVA), and response surface methodology (RSM) for modeling and optimizing the electrospinning parameters of VP nanofibers. The electrospinning control parameters studied in this work include voltage, concentration, rotational speed of the collector, needle-to-collector distance, and flow rate. The minimum fiber diameter and its variation were evaluated using Taguchi's design of experiments, and further, RSM was employed to create an empirical model out of the experimental runs. Thus, the results of this study can offer clear analysis and understanding of the electrospinning process parameters on the resultant fiber diameter of PVP.

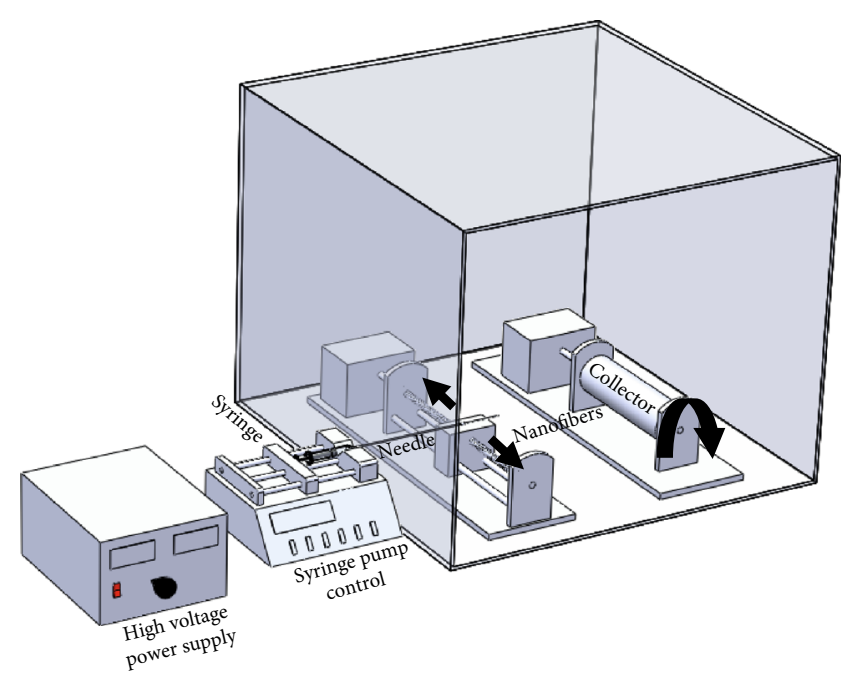

FIgURE 1: Laboratory-scale electrospinning assembly.

\section{Experimental Setup and Methodology}

2.1. Materials. Polymer polyvinylpyrrolidone (PVP) with an average molecular weight of $1,300,000 \mathrm{~g} / \mathrm{mol}$ (i.e., $100 \%$ purity) from Sigma-Aldrich, USA, and solvent ethanol of molecular weight $46.07 \mathrm{~g} / \mathrm{mol}$ (95\% purity) from ACP, Canada, were utilized as the experimental materials.

\subsection{Electrospinning of PVP. The polymeric solution of PVP} was prepared via mixing PVP powders in ethanol at different concentrations, viz., 8,10 , and $12 \mathrm{wt} \%$, by magnetic stirring for 24 hours at ambient temperature. Figure 1 shows the laboratory-scale electrospinning setup with the following components: a syringe pump (New Era Company, USA), a high-voltage power supply (Gamma High Voltage Research Inc., USA), a rotating cylindrical collector with variable speed control, and a needle holder with forward and backward motions. The $5 \mathrm{ml}$ syringe is first filled with the polymer dissolved in the solvent, and the assembled needle is connected with the positive end of the voltage power supply. The flow rate of the polymer solution can be varied via regulating the voltage from the power supply. The solution, when extruded out of the needle, forms the Taylor cone under the action of applied electrical potential and is deposited on the grounded rotating collector in the form of fibers. The complete assembly is housed in an acrylic box for safety from high voltage and solution vapors.

2.3. Design of Experiments. The selected values of the five electrospinning parameters are given in Table 2. Each parameter was assigned with a three-level variation. Taguchi's method, being simple and robust, was used in this study for the design of experiments and the optimization. The design consists of 27 rows and 13 columns $(\max )$ with three-level variation [38]. The mean output performance and variation were studied with the applied Taguchi's quality loss function design. Table 3 shows the design of experiments where the columns indicate the process parameters and the rows indicate the designated values accordingly. 
TABLE 2: Electrospinning control factors and levels.

\begin{tabular}{lcccc}
\hline & Symbol & Level 1 & Level 2 & Level 3 \\
\hline Control factors & & & & \\
High voltage $(\mathrm{kV})$ & $A$ & 10 & 13 & 15 \\
Concentration $(\mathrm{wt} \%)$ & $B$ & 8 & 10 & 12 \\
Rotational speed $(\mathrm{RPM})$ & $C$ & 500 & 1000 & 1500 \\
Collecting distance $(\mathrm{cm})$ & $D$ & 10 & 13 & 15 \\
Flow rate $(\mathrm{ml} / \mathrm{h})$ & $E$ & 0.6 & 0.8 & 1 \\
\hline
\end{tabular}

\section{Results and Discussion}

The average value and the standard deviation of the obtained fiber diameters for each trial are given in the far right column in Table 3. The reported fiber diameter is the average of at least twenty measurements of the fiber diameter at different locations on the nanofiber mat (Figures 2(a) and 2(b)). The nanosized fiber diameter values were observed from the experimental results providing an advantage of exhibiting high surface area to volume ratio that is very beneficial for sound absorption characteristics of a nanofiberbased membrane.

The results of the fiber diameter measurements suggest that the least fiber diameter values were achieved with the experimental run numbers 12,19 , and 20, namely, at the lower concentrations and higher voltage values. The least fiber diameter value was observed at the experimental run no. 19 that resulted in a diameter value of $536 \mathrm{~nm}$ at a polymer concentration of $8 \mathrm{wt} \%$, an applied voltage of $15 \mathrm{kV}$, a 500 collector RPM, a $10 \mathrm{~cm}$ collecting distance, and a low flow rate of $0.6 \mathrm{ml} / \mathrm{h}$. The corresponding fiber diameter values range from $536 \mathrm{~nm}$ to $598 \mathrm{~nm}$, and the highest diameter observed was $2.54 \mu \mathrm{m}$ as mentioned in Table 3 .

3.1. Analysis of Variance: Parametric Effect Evaluation. The evaluation of the control factors and their significance was carried out using ANOVA software where the mean output response for the individual trial at each level was investigated and is shown Table 4 . It was observed that the high voltage ( $A$ ) and polymer concentration $(B)$ introduced the significant effects on the fiber diameter. The corresponding $F$-test values confirm the significance of high voltage at $95 \%$ confidence level and concentration at $99 \%$ confidence level (i.e., looking at Table 4,F)A > F)2,16@90\% and F)2,16@95\%, and similarly, F)B > F)2,16@90\%,F)2,16@95\%, and F)2,16@99\%). On the other hand, the parameters such as collector RPM, needle-collector distance, and flow rate had the least effects and were considered to be insignificant because of its minimum statistical summation of diameter values, i.e., 0.63, 0.82 , and 1.2 (i.e., looking at Table $4, F) C, F) D$, and $F) E$ are all less than F)2,16@90\%).

3.2. Morphology of Fibers. The characteristics of the nanofibers (fiber shape, diameter, and surface structure) are affected significantly by the change in electrospinning parameters [39]. This phenomenon is explained in the SEM micrographs of PVP nanofibers (Table 5) which suggest visually that high
TABLE 3: Experimental plan for fiber diameter analysis of PVP nanofibers using L27 orthogonal array.

\begin{tabular}{|c|c|c|c|c|c|c|c|}
\hline & Run no. & $A$ & $B$ & C & $D$ & $E$ & $\begin{array}{l}\text { Fiber diameter }(\mu \mathrm{m}) \\
\quad \text { (average value) }\end{array}$ \\
\hline & 1 & 10 & 8 & 500 & 10 & 0.6 & $0.662 \pm 0.139$ \\
\hline & 2 & 10 & 8 & 1000 & 13 & 0.8 & $0.933 \pm 0.147$ \\
\hline & 3 & 10 & 8 & 1500 & 15 & 1.0 & $0.744 \pm 0.131$ \\
\hline & 4 & 10 & 10 & 500 & 13 & 1.0 & $1.253 \pm 0.191$ \\
\hline & 5 & 10 & 10 & 1000 & 15 & 0.6 & $1.243 \pm 0.227$ \\
\hline & 6 & 10 & 10 & 1500 & 10 & 0.8 & $1.527 \pm 0.358$ \\
\hline & 7 & 10 & 12 & 500 & 15 & 0.8 & $1.865 \pm 0.330$ \\
\hline & 8 & 10 & 12 & 1000 & 10 & 1.0 & $2.540 \pm 0.348$ \\
\hline & 9 & 10 & 12 & 1500 & 13 & 0.6 & $1.507 \pm 0.579$ \\
\hline & 10 & 13 & 8 & 500 & 10 & 0.6 & $0.605 \pm 0.102$ \\
\hline & 11 & 13 & 8 & 1000 & 13 & 0.8 & $0.819 \pm 0.115$ \\
\hline & 12 & 13 & 8 & 1500 & 15 & 1.0 & $0.570 \pm 0.392$ \\
\hline & 13 & 13 & 10 & 500 & 13 & 1.0 & $1.091 \pm 0.607$ \\
\hline \multirow[t]{14}{*}{ L27OA } & 14 & 13 & 10 & 1000 & 15 & 0.6 & $1.048 \pm 0.399$ \\
\hline & 15 & 13 & 10 & 1500 & 10 & 0.8 & $0.879 \pm 0.611$ \\
\hline & 16 & 13 & 12 & 500 & 15 & 0.8 & $2.075 \pm 0.380$ \\
\hline & 17 & 13 & 12 & 1000 & 10 & 1.0 & $1.299 \pm 0.754$ \\
\hline & 18 & 13 & 12 & 1500 & 13 & 0.6 & $1.120 \pm 0.672$ \\
\hline & 19 & 15 & 8 & 500 & 10 & 0.6 & $0.536 \pm 0.149$ \\
\hline & 20 & 15 & 8 & 1000 & 13 & 0.8 & $0.598 \pm 0.105$ \\
\hline & 21 & 15 & 8 & 1500 & 15 & 1.0 & $0.921 \pm 0.207$ \\
\hline & 22 & 15 & 10 & 500 & 13 & 1.0 & $0.668 \pm 0.431$ \\
\hline & 23 & 15 & 10 & 1000 & 15 & 0.6 & $1.074 \pm 0.157$ \\
\hline & 24 & 15 & 10 & 1500 & 10 & 0.8 & $0.926 \pm 0.335$ \\
\hline & 25 & 15 & 12 & 500 & 15 & 0.8 & $1.465 \pm 0.470$ \\
\hline & 26 & 15 & 12 & 1000 & 10 & 1.0 & $1.486 \pm 0.660$ \\
\hline & 27 & 15 & 12 & 1500 & 13 & 0.6 & $1.559 \pm 0.540$ \\
\hline
\end{tabular}

voltage $(10-15 \mathrm{kV})$ and concentration $(8-12 \mathrm{wt} \%)$ have significant effects on the fiber diameter. The minimum fiber diameter value of $0.536 \mu \mathrm{m}$ was observed at the lowest concentration $(8 \mathrm{wt} \%)$ and highest voltage $(15 \mathrm{kV})$. The maximum fiber diameter value of $2.54 \mu \mathrm{m}$ was obtained at the highest concentration (12 wt\%) and lowest voltage $(10 \mathrm{kV})$. The analysis shows that the average fiber diameter value decreases with a decrease in the polymer concentration and with an increase in the supplied voltage. This may be attributed due to the fact that if the polymer solution concentration is very low, the viscoelastic forces would not be sufficient enough to escape the columbic repulsion force that breaks up the jet to form fibers, and hence, it results in beads. It was noticed that to achieve uniform beadless fibers, the viscoelastic force should be sufficient to break the polymer jet with higher columbic stress that influences the jet elongation. Hence, with the further increase in concentration, the fiber diameter of the resultant fiber reduces [26]. If the solution 


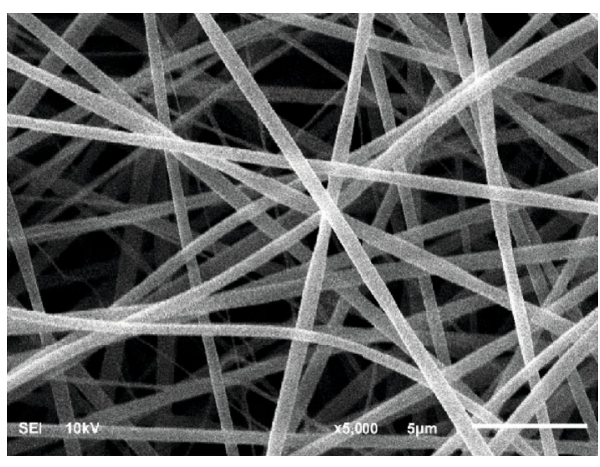

(a)

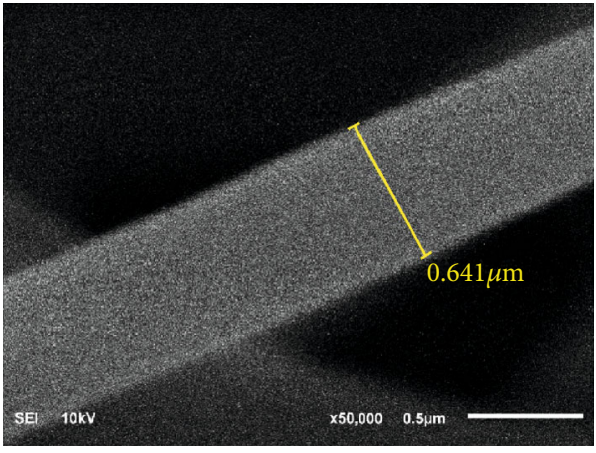

(b)

FIgURe 2: SEM image of the PVP8 nanofibers at (a) 5000x (scale: $5 \mu \mathrm{m}$ ) and (b) 50000x (scale: $0.5 \mu \mathrm{m}$ ) for fiber diameter calculation.

TABLE 4: ANOVA results for a single effect.

\begin{tabular}{|c|c|c|c|c|c|c|c|c|c|c|c|}
\hline \multicolumn{12}{|c|}{ Analysis of variance (ANOVA) } \\
\hline$A_{1}$ & 12.274 & $B_{1}$ & 6.388 & $C_{1}$ & 10.22 & $D_{1}$ & 10.451 & $E_{1}$ & 9.355 & $\mathrm{SS}_{\mathrm{T}}$ & 6.29123 \\
\hline$A_{2}$ & 9.497 & $B_{2}$ & 9.709 & $C_{2}$ & 11.031 & $\mathrm{D}_{2}$ & 9.549 & $E_{2}$ & 11.087 & & \\
\hline$A_{3}$ & 9.234 & $B_{3}$ & 14.908 & $C_{3}$ & 9.754 & $D_{3}$ & 11.005 & $E_{3}$ & 10.563 & & \\
\hline $\mathrm{SS}_{A}$ & 0.63046 & $\mathrm{SS}_{B}$ & 4.09811 & $\mathrm{SS}_{C}$ & 0.0928 & $\mathrm{SS}_{D}$ & 0.12001 & $\mathrm{SS}_{E}$ & 0.17532 & $\mathrm{SS}_{\text {Error }}$ & 1.17451 \\
\hline$V_{A}$ & 0.31523 & $V_{B}$ & 2.04905 & $V_{C}$ & 0.0464 & $V_{D}$ & 0.06000 & $V_{E}$ & 0.08766 & $V_{\text {Error }}$ & 0.07340 \\
\hline F) $A$ & 4.29428 & $F) B$ & 27.9135 & $F) C$ & 0.63209 & $F) D$ & 0.81747 & F) $B E$ & 1.19416 & & \\
\hline$p_{A}$ & 0.0321 & $p_{B}$ & 0.0001 & $p_{C}$ & 0.5442 & $p_{D}$ & 0.4592 & $p_{E}$ & 0.1758 & & \\
\hline \multicolumn{10}{|c|}{ F)2,16@90\% confidence level } & 2.66 & \\
\hline \multicolumn{10}{|c|}{ F)2,16@95\% confidence level } & 3.63 & \\
\hline \multicolumn{10}{|c|}{ F)2,16@99\% confidence level } & 6.22 & \\
\hline
\end{tabular}

TABLE 5: SEM images to study fiber morphology at different levels of polymer concentration, voltage applied, flow rate, RPM, and collection distance.

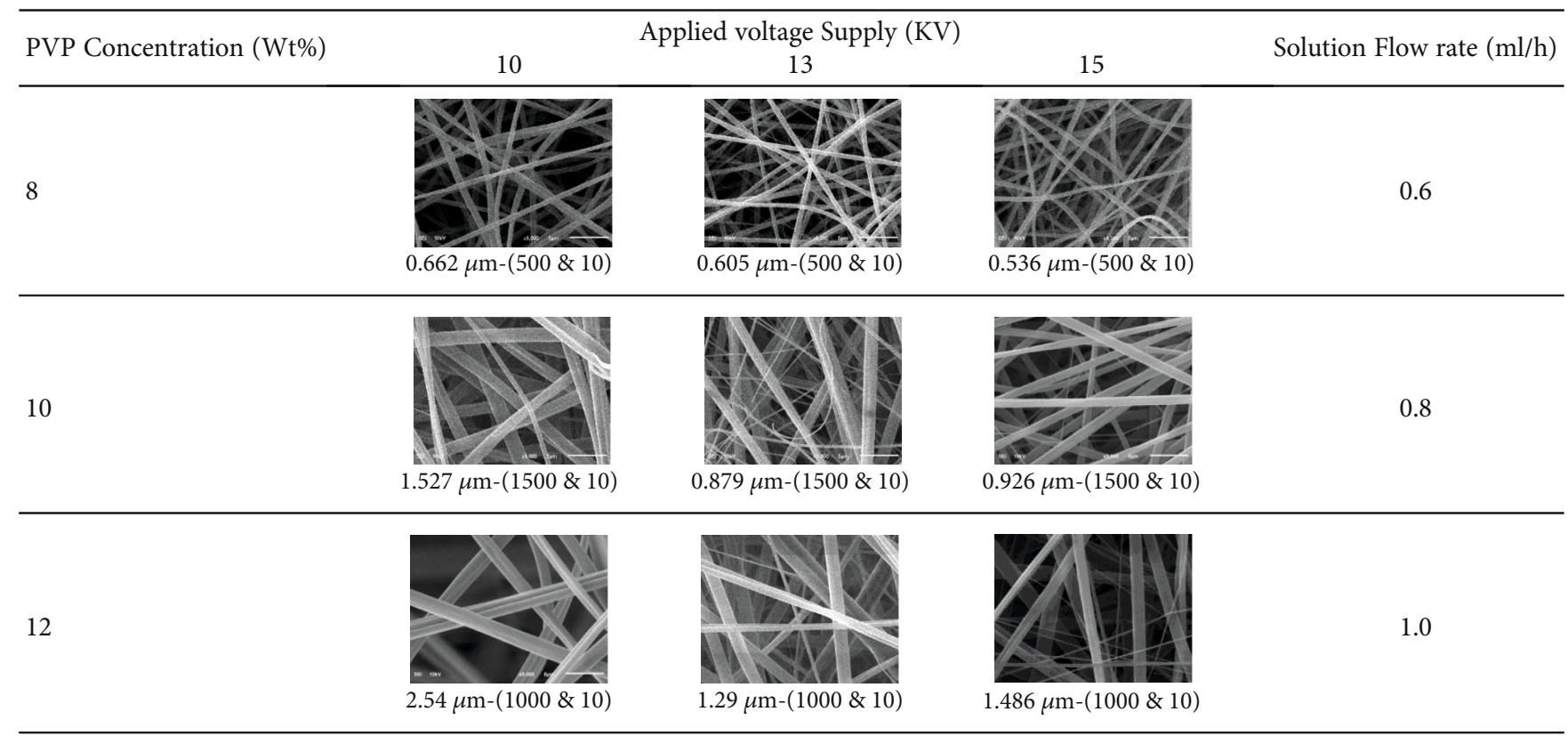

${ }^{*}$ Fiber diameter $(\mu \mathrm{m})$-(RPM \& Needle to collector distance - $\left.\mathrm{cm}\right)$. 
concentration is high, the fiber diameter will increase substantially, and if concentration is too high, it will restrict the continuous flow and the needle will be blocked [40]. Furthermore, the fiber diameter value decreases with the increase in high voltage because the amount of charge flowing in a jet increases which in turn increases the repulsion force. The increased repulsion force increases the stretching force acting on the polymer jet leading to the development of thinner fibers [41]. At $8 \mathrm{wt} \%$ concentration (voltage range: $10-15 \mathrm{kV}$ ), a substantial number of thin uniform fibers of an average diameter less than $0.7 \mu \mathrm{m}$ were observed with a narrow range of diameters. On the other hand, at higher concentrations of $10-12 \mathrm{wt} \%$ (voltage range: $10-15 \mathrm{kV}$ ), an adequate amount of mixed fibers (thin and thick) were observed with the increase in applied voltage. A similar phenomenon is also reported in few works that studied electrospinning of PVP $[42,43]$. The broader distribution may be attributed because of the increased electric field intensity that influences thin fiber generation. Furthermore, at higher concentrations, fibers are stretched out in different shapes and some are twisted to each other in various patterns $[26,40,41]$. The reason is the difference in the stretching force on the polymer jet and the electrostatic force of attraction between fibers that is exposed to a higher electric field [16, 17]. Moreover, higher surface tension of the polymer solution prevents the decrease in size of the jet extruding out from the needle and fibers subside on each other when the solvent dries up [26].

\subsection{Effect of Electrospinning Parameters/Control Factors. The} graphical representation of the summation values of the fiber diameter is plotted with the corresponding control variable/factor in Figure 3. A substantial variation in diameter values was observed for the different levels of concentration and high voltage which is an indication of the high significance of these factors compared to others. There are many controversial results on the effect of high voltage on the fiber diameter as there are reports that says it increases with the increase in voltage for PVA polymer solution [16]. On the other hand, few reports on electrospinning of PVP investigated that the fiber diameter decreases with an inceptive increase in voltage that enhances the repulsion force. A further increase in the intensity of the electric field increases the diameter which may be because of the high electrostatic force [26]. Several other researchers investigated the controversial result with electrospun PVP nanocomposites [44-46]. The effect of the as-mentioned forces, viz., repulsion and electrostatic forces, might be the reason of the conflict in the variation of the diameter with voltage. The high voltage in comparison with the other factors, viz., flow rate, needle-collector distance, and collector RPM, had significant effects on the diameter. This phenomenon is in close agreement with the work where the diameter of PVP nanofibers decreases with the increase in voltage up to $15 \mathrm{kV}$ except for the increase in the diameter with the further increase in voltage [26]. Other polymer materials like PSF in acetone [17] and poly-(lactide-co-glycolide) (PLAGA) [18] were reported to be in accordance with the same phenomenon. Hence, voltage has an effect on the diameter but its significance depends on the variation level, polymer, and its concentration [21]. It was found that with

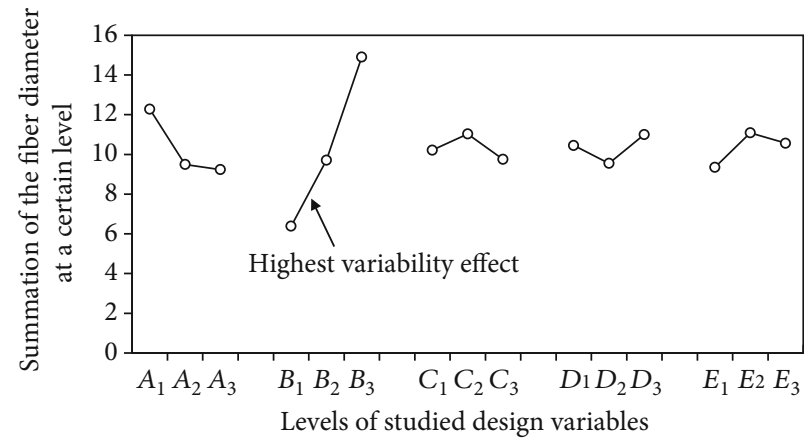

FIGURE 3: Graphical representation of the main effects of electrospinning control factors.

the increase in the high-voltage supply from $A_{1}$ to $A_{3}$ (10 to $15 \mathrm{kV})$ and the decrease in the concentration from $B_{3}$ to $B_{1}$ (12 to $8 \mathrm{wt} \%$ ), the fiber diameter values decreased and reached a minimum value. This may be because a higher voltage increases the repulsive forces which in turn increases the polymer solution stretching, resulting in a smaller fiber diameter [28, 29]. A higher fiber diameter variation was observed with an increase in concentration because of an increase in the amount of polymer content in the extruded jet from the Taylor cone. At this point, the thicker jet travels towards the collector end which leads to the thicker fibers and sometimes beads [47]. Further, the differences between the maximum and minimum summation values for the factors, applied voltage and concentration, were observed to be 3.04 and 8.52, respectively, which were the highest compared with those of the other factors (rotational speed, collecting distance, and flow rate), viz., 1.28, 1.456, and 1.732. It confirms the significant effects of these factors on the output fiber diameter values. The analysis confirms that the polymer concentration is the most prominent factor with the highest variability effect whereas the other factors, namely, RPM, flow rate, and distance, do not seem to have any significant effect on the diameter values. Finally, it should be stated that all results are valid within the provided ranges (see Table 2) for all studied design variables.

3.4. Response Surface Methodology (RSM). The significance of individual factors influencing the output response was investigated using multiple regression techniques. The mathematical model was developed for the fiber diameter response using RSM to predict the accuracy of the electrospinning model. The study investigates the effect of five parameters with three levels which leads to $3^{5}=243$ trials for complete analysis, but the orthogonal array design reduces it to 27 trials. The mathematical model developed for the single effect of the process variables on output response is represented by the following equation:

$$
\begin{aligned}
Y=- & 0.00277 * A^{2}+0.01188 * B^{2}-0.00000003482 \\
& * C^{2}+0.0004182 * D^{2}+0.1924 * E^{2}+\varepsilon,
\end{aligned}
$$

where $(\varepsilon)=0.22815$ is the error normally distributed on output response $Y$. 


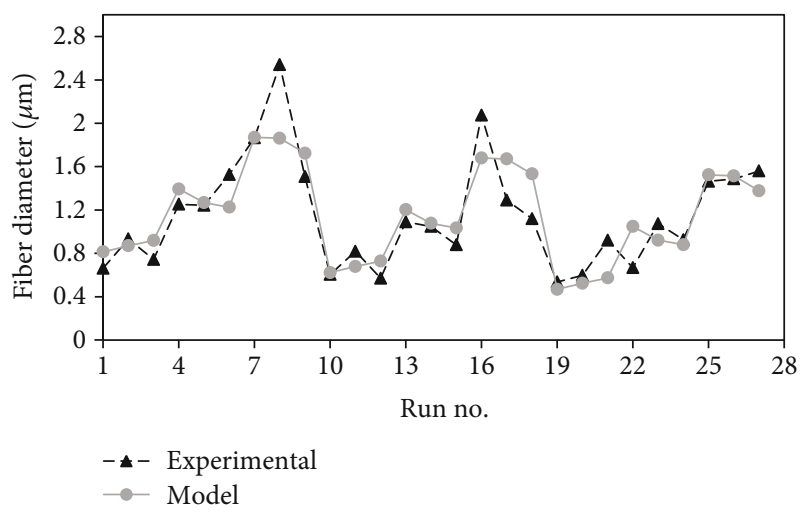

FIGURE 4: Mathematical model validation with experimental results.

The average model accuracy of the model can be calculated as follows:

$$
\operatorname{Accuracy}(A)=\left[1-\operatorname{ABS} \frac{(Y \exp .-Y)}{Y \exp .}\right] * 100 .
$$

The graphical representation shown in Figure 4 compares the mathematical model with the experimental results to analyze the model accuracy. The average model accuracy of $83.4 \%$ was obtained for the entire experimental trials, whereas a model accuracy of $90-98 \%$ was observed for the few individual runs. Overall, the calculated average accuracy is considered the acceptable range for model verification. The model accuracy can be increased by increasing the number of experimental runs or by including the interaction effect model. However, that will require more resources, and thus, it should be stated that such methodology is implemented to save time and cost through using L27OA which has been used in different applications in the open literature.

\section{Conclusions}

In this work, an attempt has been done to investigate the electrospinning process of fabricating PVP nanofibers, and the parametric study of the process was investigated. The effects of five major parameters, namely, high voltage, polymer concentration, collector RPM, needle tip-collector distance, and flow rate of the polymer solution, were studied using Taguchi L27OA with three levels at each parameter. It was found that the electrospun PVP fibers obtained were in the range of $536 \mathrm{~nm}$ to $2.54 \mu \mathrm{m}$. The minimum fiber diameter was found to be controlled by two main design variables, i.e., polymer concentration and voltage applied, as both showed significant effects on the measured fiber morphology. On the other hand, the flow rate, RPM, and collecting distance had the least significant effects compared to the other two. The smallest fiber diameter was obtained at the highest voltage level $(15 \mathrm{kV})$ and the lowest concentration $(8 \mathrm{wt} \%)$, with a flow rate of $0.6 \mathrm{ml} / \mathrm{h}$. The ANOVA test confirms the significance of these factors at $95 \%$ confidence level for voltage and $99 \%$ confidence level for concentration. The mathematical model developed using RSM predicted the model accuracy of $83.4 \%$ for the range of the chosen control parameters. This research work offers a valuable understanding of the effect of various electrospinning parameters on the structural integrity of PVP nanofibers. In terms of the future work, another phase will be carried out to model the effect of the fiber diameter on sound absorption coefficient values of nanofiber membranes prepared from PVP nanofibers.

\section{Data Availability}

The data used to support the findings of this study are included within the article

\section{Conflicts of Interest}

The authors declare that they have no conflicts of interest.

\section{Acknowledgments}

The authors are grateful to NSERC's Discovery Grant, NSERC's Discovery Development Grant, and NSERC's Chairs in Design Engineering Program for the financial support of this research.

\section{References}

[1] W. E. Teo and S. Ramakrishna, "A review on electrospinning design and nanofibre assemblies," Nanotechnology, vol. 17, no. 14, pp. R89-R106, 2006.

[2] F. E. Ahmed, B. S. Lalia, and R. Hashaikeh, "A review on electrospinning for membrane fabrication: challenges and applications," Desalination, vol. 356, pp. 15-30, 2015.

[3] J. Doshi and D. H. Reneker, "Electrospinning process and applications of electrospun fibers," Journal of Electrostatics, vol. 35, no. 2-3, pp. 151-160, 1995.

[4] W. Lu, J. Sun, and X. Jiang, "Recent advances in electrospinning technology and biomedical applications of electrospun fibers," Journal of Materials Chemistry B, vol. 2, no. 17, pp. 2369-2380, 2014.

[5] R. Asmatulu, M. B. Yildirim, W. S. Khan, A. Adeniji, and H. L. Wamocha, Nanofiber fabrication and characterization for the engineering education, 2007 ASEE Midwest Regional Conference, 2007.

[6] A. K. Haghi and M. Akbari, "Trends in electrospinning of natural nanofibers," Physica Status Solidi (A), vol. 204, no. 6, pp. 1830-1834, 2007.

[7] M. Ziabari, V. Mottaghitalab, and A. K. Haghi, "Application of direct tracking method for measuring electrospun nanofiber diameter," Brazilian Journal of Chemical Engineering, vol. 26, no. 1, pp. 53-62, 2009.

[8] Z. Li and C. Wang, One- Dimensional Nanostructures: Electrospinning Technique and Unique Nanofibers, Springer, 2013.

[9] C. J. Thompson, G. G. Chase, A. L. Yarin, and D. H. Reneker, "Effects of parameters on nanofiber diameter determined from electrospinning model," Polymer, vol. 48, no. 23, pp. 69136922, 2007.

[10] J. Tao and S. Shivkumar, "Molecular weight dependent structural regimes during the electrospinning of PVA," Materials Letters, vol. 61, no. 11-12, pp. 2325-2328, 2007.

[11] J. M. Deitzel, J. Kleinmeyer, D. Harris, and N. C. B. Tan, "The effect of processing variables on the morphology of 
electrospun nanofibers and textiles," Polymer, vol. 42, no. 1 , pp. 261-272, 2001.

[12] A. Koski, K. Yim, and S. Shivkumar, "Effect of molecular weight on fibrous PVA produced by electrospinning," Materials Letters, vol. 58, no. 3-4, pp. 493-497, 2004.

[13] E. D. Boland, G. E. Wnek, D. G. Simpson, K. J. Pawlowski, and G. L. Bowlin, "Tailoring tissue engineering scaffolds using electrostatic processing techniques: a study of poly (glycolic acid) electrospinning," Journal of Macromolecular Science, Part A, vol. 38, no. 12, pp. 1231-1243, 2001.

[14] S. N. Patra, A. J. Easteal, and D. Bhattacharyya, "Parametric study of manufacturing poly (lactic) acid nanofibrous mat by electrospinning," Journal of Materials Science, vol. 44, no. 2, pp. 647-654, 2009.

[15] D. H. Reneker and I. Chun, "Nanometre diameter fibres of polymer, produced by electrospinning," Nanotechnology, vol. 7, no. 3, pp. 216-223, 1996.

[16] C. Zhang, X. Yuan, L. Wu, Y. Han, and J. Sheng, "Study on morphology of electrospun poly(vinyl alcohol) mats," European Polymer Journal, vol. 41, no. 3, pp. 423-432, 2005.

[17] X. Yuan, Y. Zhang, C. Dong, and J. Sheng, "Morphology of ultrafine polysulfone fibers prepared by electrospinning," Polymer International, vol. 53, no. 11, pp. 1704-1710, 2004.

[18] D. S. Katti, K. W. Robinson, F. K. Ko, and C. T. Laurencin, "Bioresorbable nanofiber-based systems for wound healing and drug delivery: optimization of fabrication parameters," Journal of Biomedical Materials Research Part B: Applied Biomaterials, vol. 70B, no. 2, pp. 286-296, 2004.

[19] R. Dersch, T. Liu, A. K. Schaper, A. Greiner, and J. H. Wendorff, "Electrospun nanofibers: internal structure and intrinsic orientation," Journal of Polymer Science Part A: Polymer Chemistry, vol. 41, no. 4, pp. 545-553, 2003.

[20] H. Niu, X. Wang, and T. Li, "Needleless electrospinning: developments and performances," in Nanofibers-Production, Properties and Functional Applications, pp. 17-36, 2011.

[21] O. S. Yördem, M. Papila, and Y. Z. Menceloğlu, "Effects of electrospinning parameters on polyacrylonitrile nanofiber diameter: an investigation by response surface methodology," Materials \& Design, vol. 29, no. 1, pp. 34-44, 2008.

[22] D. H. Reneker, A. L. Yarin, H. Fong, and S. Koombhongse, "Bending instability of electrically charged liquid jets of polymer solutions in electrospinning," Journal of Applied Physics, vol. 87, no. 9, pp. 4531-4547, 2000.

[23] O. Karatay and M. Dogan, "Modelling of electrospinning process at various electric fields," Micro \& Nano Letters, vol. 6, no. 10 , pp. 858-862, 2011.

[24] T. A. Kowalewski, S. Barral, and T. Kowalczyk, "Modeling electrospinning of nanofibers," in IUTAM Symposium on Modelling Nanomaterials and Nanosystems. IUTAM Bookseries, vol 13, R. Pyrz and J. C. Rauhe, Eds., pp. 279-292, Springer, Dordrecht, 2009.

[25] T. Kowalewski, S. Nski, and S. Barral, "Experiments and modelling of electrospinning process," Bulletin of the Polish Academy of Sciences, vol. 53, no. 4, pp. 385-394, 2005.

[26] S. Chuangchote, T. Sagawa, and S. Yoshikawa, "Electrospinning of poly(vinyl pyrrolidone): effects of solvents on electrospinnability for the fabrication of poly(p-phenylene vinylene) and $\mathrm{TiO}_{2}$ nanofibers," Journal of Applied Polymer Science, vol. 114, no. 5, pp. 2777-2791, 2009.
[27] D. Li, Y. Wang, and Y. Xia, "Electrospinning of polymeric and ceramic nanofibers as uniaxially aligned arrays," Nano Letters, vol. 3, no. 8, pp. 1167-1171, 2003.

[28] J. S. Lee, K. H. Choi, H. D. Ghim et al., "Role of molecular weight of atactic poly (vinyl alcohol)(PVA) in the structure and properties of PVA nanofabric prepared by electrospinning," Journal of Applied Polymer Science, vol. 93, no. 4, pp. 1638-1646, 2004.

[29] C. J. Buchko, L. C. Chen, Y. Shen, and D. C. Martin, "Processing and microstructural characterization of porous biocompatible protein polymer thin films," Polymer, vol. 40, no. 26, pp. 7397-7407, 1999.

[30] S. Zhao, X. Wu, L. Wang, and Y. Huang, "Electrospinning of ethyl-cyanoethyl cellulose/tetrahydrofuran solutions," Journal of Applied Polymer Science, vol. 91, no. 1, pp. 242-246, 2004.

[31] N. Li, J. Xiong, and H. Xue, "Effect of wheel rotating speed and $\mathrm{LiCl}$ additives on electrospun aligned polyacrylonitrile nanofiber," Polymer Engineering \& Science, vol. 51, no. 11, pp. 21782183, 2011.

[32] N. Bhardwaj and S. C. Kundu, "Electrospinning: a fascinating fiber fabrication technique," Biotechnology Advances, vol. 28, no. 3, pp. 325-347, 2010.

[33] Q. P. Pham, U. Sharma, and A. G. Mikos, "Electrospinning of polymeric nanofibers for tissue engineering applications: a review," Tissue Engineering, vol. 12, no. 5, pp. 1197-1211, 2006.

[34] H. Albetran, Y. Dong, and I. M. Low, "Characterization and optimization of electrospun $\mathrm{TiO}_{2} / \mathrm{PVP}$ nanofibers using Taguchi design of experiment method," Journal of Asian Ceramic Societies, vol. 3, no. 3, pp. 292-300, 2015.

[35] Y. Dong, T. Bickford, H. J. Haroosh, K.-T. Lau, and H. Takagi, "Multi-response analysis in the material characterisation of electrospun poly (lactic acid)/halloysite nanotube composite fibres based on Taguchi design of experiments: fibre diameter, non-intercalation and nucleation effects," Applied Physics A, vol. 112, no. 3, pp. 747-757, 2013.

[36] M. Kucukali Ozturk, B. Nergis, C. Candan, and K. Kalinova, "A study on the effect of fiber diameter on the acoustic behavior of the nanofibrous membrane," in The Fiber Society Spring 2014 International Conference, pp. 21-23, 2014.

[37] K. Kalinová, "Nanofibrous resonant membrane for acoustic applications," Journal of Nanomaterials, vol. 2011, 6 pages, 2011.

[38] M. Elkasaby, H. A. Hegab, A. Mohany, and G. M. Rizvi, "Modeling and optimization of electrospinning of polyvinyl alcohol (PVA)," Advances in Polymer Technology, vol. 37, no. 6, 2122 pages, 2018.

[39] K. Magniez, C. de Lavigne, and B. L. Fox, "The effects of molecular weight and polymorphism on the fracture and thermo- mechanical properties of a carbon-fibre composite modified by electrospun poly (vinylidene fluoride) membranes," Polymer, vol. 51, no. 12, pp. 2585-2596, 2010.

[40] Q. Yang, Z. Li, Y. Hong et al., "Influence of solvents on the formation of ultrathin uniform poly (vinyl pyrrolidone) nanofibers with electrospinning," Journal of Polymer Science Part B: Polymer Physics, vol. 42, no. 20, pp. 3721-3726, 2004.

[41] M. M. Hohman, M. Shin, G. Rutledge, and M. P. Brenner, "Electrospinning and electrically forced jets. I. Stability theory," Physics of Fluids, vol. 13, no. 8, pp. 2201-2220, 2001. 
[42] X. Li, L. Lin, Y. Zhu, W. Liu, T. Yu, and M. Ge, "Preparation of ultrafine fast-dissolving cholecalciferol-loaded poly (vinyl pyrrolidone) fiber mats via electrospinning," Polymer Composites, vol. 34, no. 2, pp. 282-287, 2013.

[43] L. Mei, R. Han, Y. Gao, Y. Fu, and Y. Liu, "Effect of electric field intensity on the morphology of magnetic-field-assisted electrospinning PVP nanofibers," Journal of Wuhan University of Technology-Mater. Sci. Ed., vol. 28, no. 6, pp. 11071111, 2013.

[44] D. Li and Y. Xia, "Fabrication of titania nanofibers by electrospinning," Nano Letters, vol. 3, no. 4, pp. 555-560, 2003.

[45] Y. Xin, Z. Y. Huang, E. Y. Yan, W. Zhang, and Q. Zhao, “Controlling poly (p-phenylene vinylene)/poly (vinyl pyrrolidone) composite nanofibers in different morphologies by electrospinning," Applied Physics Letters, vol. 89, no. 5, article 053101, 2006.

[46] Y. Jin, X. Lu, and C. Wang, "Fabrication of discontinuous fibers of poly (N-vinylpyrrolidone) containing metalloporphyrin molecules," Journal of Applied Polymer Science, vol. 102, no. 6, pp. 6017-6022, 2006.

[47] G. R. Mitchell, Electrospinning: Principles, Practice and Possibilities, Royal Society of Chemistry, 2015. 